\title{
Campaign finance vouchers do not reduce donor inequality
}

\author{
Chenoa Yorgason*
}

July 8, 2021

\begin{abstract}
Donating to a campaign is inherently costly, and as a result, the composition of campaign donors differs from the composition of the electorate. What happens when the financial barriers to participation in campaign finance are removed? This paper analyzes Seattle's recent campaign finance reforms, where all registered voters receive four $\$ 25$ vouchers to donate to candidates abiding by stricter campaign finance restrictions. Utilizing individualand census block group-level data combined with administrative donation records, I find that those most mobilized by the availability of vouchers belong to groups already overrepresented within the donor pool. In many cases, the availability of vouchers appears to pull the donor pool even further from parity within the electorate. This finding is significant across race, income, past political participation, age, and partisanship.
\end{abstract}

\footnotetext{
${ }^{*}$ Chenoa Yorgason is a PhD candidate and Melvin and Joan Lane Fellow at Stanford University (chenoa@stanford.edu). The protocol for this study was approved by Stanford's IRB (protocol 61828). For helpful comments and discussion, the author thanks Adam Bonica, Justin Grimmer, Andy Hall, Katie Clayton, and Cole Tanigawa-Lau.
} 
Campaign finance vouchers have recently emerged as a popular policy proposal to address inequality of influence in elections in a post-Citizens United world. In contrast to more traditional campaign financing methods, such as those that reduce reliance on fundraising or amplify small donations by a multiplicative factor, campaign finance vouchers force candidates to still fundraise, while eliminating the financial burden on individuals. On the national scale, 2020 Democratic presidential candidates Andrew Yang, Bernie Sanders, and Kirsten Gillibrand incorporated innovative campaign financing schemes into their platforms (Gillibrand, 2019, Sanders, 2020, Yang, 2020). Gillibrand wrote that vouchers would "amplif[y] the voices of Americans who haven't been heard for too long." Yang claimed that by "mak[ing] it possible for all Americans to contribute to candidates they feel strongly about" the program would "allow the will of the people to shine through." While a voucher program was not part of President Biden's platform, campaign finance vouchers are neither a new nor fleeting policy proposal. The 117th Congress' H.R. 1 (117th Congress, 2021) introduces a pilot program which would give individuals in three states vouchers to donate to Congressional candidates of their choosing. Similar programs were proposed in the 116th and 114th Congresses. At the state and local level, propositions and initiatives in Albuquerque, Austin, and South Dakota have been considered, though ultimately failed. However, campaign finance vouchers have been implemented in Seattle, where voters approved the Democracy Voucher program in 2015.

The purpose of campaign finance vouchers, as opposed to a campaign finance schemes that strictly limit individual involvement such as standalone donation maximums, is to make the donor pool more representative of the public while also lowering reliance on private dollars. To evaluate if these programs "amplify the voices of Americans who haven't been heard for too long," we must rigorously examine who takes advantage of these innovations. With individual-level contribution, electoral, and demographic data, I use a difference-indifferences approach to examine the causal effects of vouchers on the representativeness of the donor pool in Seattle. Among all groups, participation in campaign finance post- 
reform increased. However, in contrast to the expectations of reformers, those benefiting from the presence of vouchers are the same kinds of people who already dominated the cash donor pool: they are richer, whiter, more liberal, more Democratic, older, and vote more. Though the influence of any given high-dollar donor may have waned, vouchers are linked to unrepresentative movement within the donor pool.

In this paper, I examine the impact of vouchers on donor pool diversity by combining multiple sets of individual-level administrative data. Campaign contribution data from Seattle City Council and City Attorney elections from 2005 to 2019 are merged with demographic data and voting histories from a similar time span. This data is further joined with administrative data from federal elections contributions and census block groups demographics. With this new dataset, I identify individuals who resided in Seattle in all eight municipal electoral cycles 2005-2019, and am able to analyze their municipal donations over time. In contrast to policy evaluations that only compare aggregate rates of participation (which do not necessarily reflect individual-level behavior) or only compare a single year's voucher donors to same-year cash donors or to the cash donors of a single prior year (which assume that all voucher-only donors would not donate without vouchers available), this paper leverages rich individual-level data across two treatment periods and six pre-treatment periods. This time series of municipal electoral contributions offers the best leverage to examine the impact of vouchers on donor diversity, as voucher-era donation behavior can be appropriately compared to pre-voucher donation histories among the same individuals.

\section{Inequality and political participation}

At the national level, participation in the campaign finance process is skewed in favor of certain groups. Racial minorities (Grumbach \& Sahn, 2019), women (Ingalls \& Arring-

ton, 1991), women of color (Grumbach et al., 2020), the non-wealthy (Brady et al., 1995; Overton, 2004), moderates (Broockman \& Malhotra, 2020), and ideologically unsophisti- 
cated Americans (Barber et al., 2017) are underrepresented in the campaign finance process. This paper considers campaign finance within local elections, where electoral inequalities are often even more severe than inequalities within federal elections. Examinations of local elections have found that participation tends to skew towards older residents, homeowners, and the educated (Oliver \& Ha, 2007) and that the off-federal-cycle timing of local elections can exacerbate inequality in participation (Hajnal and Trounstine, 2005; Kogan et al., 2018) and serve to further the agenda of special-interest groups (Anzia, 2011).

In many cases, egalitarian (restrictive) policies do not necessarily have egalitarian (restrictive) outcomes. Work in political science largely focuses on the differential impacts of policies on electoral turnout. Recent studies about the impact of voter identification laws on minority turnout have generated controversial and varying estimates (Alvarez et al., 2008; Atkeson et al., 2010; Grimmer et al., 2018; Hajnal et al., 2017), sometimes indicating that voter ID laws have negative impacts on turnout, and sometimes indicating that minority turnout remains the same or increases after restrictive voting laws. Some studies on universal vote-by-mail have found that vote-by-mail increases turnout the most among individuals with lower past political participation (Gerber et al., 2013), as well as young voters, bluecollar workers, the less educated, and racial minorities (Bonica et al., 2021).

However, other work finds that electoral reform translates to negative effects for the resource-poor (Berinsky et al., 2001) such as the less-educated, politically uninterested, and the younger. Berinsky (2005) explains that this is because reforms fail to mobilize nonvoters to join the electorate, while making consistent and frequent participation even easier for previously "transient" voters (those who usually vote but sometimes fail to due to the idiosyncrasies of life). Studies beyond Berinsky's Oregon papers suggest that this might continue to be the case. Kousser and Mullin (2007) find that assignment to mail voting disproportionately lowers turnout among citizens who are nonwhite, younger, and not members of a major political party. While McCabe and Heerwig (2019) use 2017 data to conclude 
that Democracy Vouchers "moved the voter pool in a more egalitarian direction," ${ }^{1}$ they also find that members of overrepresented groups utilized vouchers more than members of underrepresented groups. Blanket mobilization efforts additionally fail to close the participation gap. Participation encouragement studies in cities such as Seattle with Democracy Vouchers (Henderson \& Han, 2021) and Philadelphia with vote-by-mail (Hopkins et al., 2021) have found little or negative net gains in minority participation relative to white participation.

Inequalities within the donor class may impact the types of candidates elected. Dominant and non-dominant groups donate to different types of candidates. Individuals often give to candidates who would be descriptive representatives, in both gender (Barber et al., 2016; Ingalls and Arrington, 1991; Thomsen and Swers, 2017) and racial (Grumbach and Sahn, 2019; Grumbach et al., 2020; Tam Cho, 2002) contexts, thereby helping would-be descriptive representatives win elections. Therefore, if certain groups rarely donate, candidates from these groups may then disproportionately struggle to raise funds for a successful campaign.

Inequalities in participation may then impact the type of policy created, both through the election of underrepresented candidates as well as through donor access. The policy preferences of the underrepresented vary from those of the overrepresented (Gilens, 2009), so the election of underrepresented candidates can offer the underrepresented substantive representation in addition to descriptive representation. The election of candidates with underrepresented backgrounds has positive outcomes for both underrepresented demographics (Banducci et al., 2004; Chattopadhyay and Duflo, 2004; Pantoja and Segura, 2003) as well

\footnotetext{
${ }^{1}$ They find that along the dimensions of race, age, and income, voucher users are more representative of the electorate. Their conclusions differ from those made within this paper for the following reasons. First, their strategy for making this conclusion is to use an analysis similar to a 2017-only slice of Figure 2, while my main empirical strategy considers disparities in past time periods and utilizes individual fixed effects. Second, they differentiate in between qualifying cash donors (who are early donors and much more diverse) and other cash donors, so that the difference in between voucher users and (non-qualifying) cash donors is starker. Furthermore, the counterfactual for which voucher users are compared against are (non-qualifying) cash donors. For this to be a properly-identified counterfactual, it must be assumed that qualifying donors and voucher donors would not have donated without the Democracy Voucher program, a situation for which they do not present evidence.
} 
as for the district as a whole (Anzia \& Berry, 2011). More directly, policymakers are more responsive to meeting with campaign donors (Kalla \& Broockman, 2016).

In sum, strong disparities persist in campaign finance participation, and these disparities have downstream effects on who is elected and their priorities. Campaign finance reforms have the potential to lessen disparities in campaign finance participation, though this is not a foregone conclusion. To assess the efficacy of vouchers on participation, this paper examines the effects of Seattle's Democracy Voucher program.

\section{Data and Methods}

Seattle's Democracy Voucher program, which distributes vouchers to all registered voters, provides a good opportunity to evaluate the effectiveness of vouchers. In municipal elections since 2017, registered voters residing in Seattle have been able to give up to $\$ 100$, in $\$ 25$ increments and with no monetary cost to the donors, to City Council and Attorney (and in 2021, mayoral) candidates who both agree to stricter campaign finance regulations and meet a threshold of initial qualifying donations. Each year, a vast majority of candidates register to participate in the Democracy Voucher program. Physical barriers to utilizing Democracy Vouchers are low, as participants can assign their vouchers through mail, online, or through a candidate.

Data used in this paper originate from six sources: the Seattle Elections and Ethics Commission (SEEC), ${ }^{2}$ the Washington Secretary of State (SoS), L2, the Census Bureau, the Federal Elections Commission (FEC), and the Database on Ideology, Money in Politics, and Elections (DIME) (Bonica, 2016). Data and merging procedures are briefly discussed here, and are described at length in A1.1.2.

\footnotetext{
${ }^{2}$ Statewide data from the Washington Public Disclosure Commission includes addresses for donors. However, this does not include Democracy Voucher users, and does not span all the way to 2005. In order to have a standardized matching procedure for all contributions, the address-less SEEC is used instead.
} 
Table 1 - Information included in data sources

\begin{tabular}{lllll}
\hline \hline Source & Unit & Information & Time & Merges to SoS on \\
\hline SoS & individual & voting history, age & $2006-2019$ & \\
Census & block group & race & 2010 & block group \\
Census (ACS) & block group & income & 2019 & block group \\
FEC & individual & federal contributions & $2005-2020$ & name, address \\
L2 & individual & income, race, party & Dec 2019 & Voter ID \\
DIME & individual & ideology & $2008-2014$ & name, address \\
SEEC & individual & local contributions & $2005-2019$ & name, ZIP \\
\hline \hline
\end{tabular}

To construct a panel of Seattle residents who were continuously eligible to participate in Seattle elections, I identify the universe of individuals who were registered to vote in Seattle using the voter files nearest to each of the 2005 to 2019 municipal elections. This amounts to 165877 individuals, or 1,327,016 individual-cycles. The state of Washington is proactive in maintaining its voter file, and individuals who move and die are quickly purged (Wu et al., 2020).

The voter file provides an individual's age and voting history, and data from L2, an independent vendor, is used for estimates of individual partisanship, income, and race. ${ }^{3}$ To skirt possible bias that may originate from L2's modelled race, income, and partisanship measurement techniques, I additionally utilize Census and American Community Survey (ACS) block group data on income and race, and aggregate contributor ideology scores by block group with DIME data. Census block groups are the unit of analysis above census blocks, and are smaller than census tracts. There are 476 block groups, with an average of 348 individuals within the constant-residing panel (block groups generally have in between 600 and 3,000 residents).

In order to aggregate these datasets together, I conducted a series of merges based on available links, as outlined in Table 1. Because contributor data often contains nicknames,

\footnotetext{
${ }^{3}$ Section A1.2 validates income and race estimations using candidate data, and contains L2's explanation on partisanship estimation.
} 
misspellings, and abbreviations, I utilize both partial- and exact-matching when conducting name-address and name-ZIP merges.

This paper conceptualizes participation in campaign finance to be a binary action and is concerned about who donates instead of how much is donated. This metric is preferred for two reasons. First, the "Democracy"-centered nature of the voucher programs emphasizes that its primary purpose is to mobilize the citizenry, not just to disrupt big donors. If lawmakers primarily seek to disrupt big donors, they may instead implement universal contribution limits or a public financing system that deemphasizes fundraising. Second, a contribution maximum was put in place for voucher-accepting candidates as part of Seattle's I-22, which would likely impact donation totals but not the binary act of donating. As a result, if the dependent variable was total per-person contributions, the impact of vouchers and donation maximums may be conflated. While contribution maximums are often packaged alongside voucher legislation, this paper aims to examine the impact of vouchers, not of campaign finance reform as a whole. Nonetheless, A4 replicates the main findings using contribution totals, and finds similar results.

\section{Models}

In addition to presenting descriptive data, I estimate two similar continuous differencein-difference models. Model 1, each observation is a census block group-year. Participation, represented by $y$, is a binary variable that indicates participation in campaign finance in year $t$ in block group $b$. I utilize four different demographic variables: percentage white, median household income, mean voting frequency, and mean ideology within block group b. For clarity, the following models and explanations in this section are described in terms of income, though models are presented for all aforementioned demographic variables. $\beta$ is the outcome of interest and measures whether block groups with higher levels of income are associated with greater increases in campaign finance participation in voucher years. $\gamma_{b}$ and 
$\delta_{t}$ are block group and cycle fixed effects, respectively.

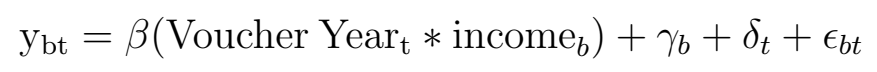

Model 2 is similar to Model 1, but utilizes individual $i$ data from L2 and the voter file instead of block group-level data. Again, for clarity, the following model describes the effects of income (decile), but models using race, partisanship, and past political participation are presenting in the results. ${ }^{4}$ I also consider age, but because the relationship between age and participation is quadratic (see Figure 1), I utilize two models to convey the behavior of individuals under 71 as well as the behavior of individuals over 70 .

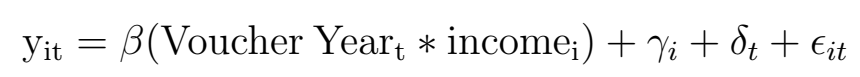

As all individuals in Seattle are simultaneously treated, with everyone becoming eligible to use vouchers in 2017, the counterfactual in this continuous difference-in-differences specification is not the same unit pre-treatment, nor is it an untreated unit. Rather, using Model 1 as an example, $\beta$ represents the additional voucher-year disparity in the conditional average treatment effect in between block groups as median income varies. A $\$ 1000$ difference in block group median income is associated with a $\beta \%$ difference in a block group's voucher year campaign finance participation. If disparities between units remain the same in voucher years, $\beta$ would be statistically insignificant.

The assumptions for these difference-in-differences models are similar to a standard difference-in-differences setup (Angrist and Pischke, 2008, Lueders et al., 2017, Thompson and Nowacki, 2021). That is, in addition to standard OLS assumptions, $\beta$ 's identification relies on the assumption that in the absence of campaign finance vouchers, disparities in participation would remain the same. Though this is not possible to observe, pre-voucher

\footnotetext{
${ }^{4}$ While gender donation gaps are present in federal data, the gender donation gap in Seattle municipal
} elections approached parity prior to the introduction of vouchers. 
trends in between block groups in the pre-treatment period can be visually assessed in Figure A3. Though block group participation varies each cycle, aggregating block groups into quartiles results in relatively parallel trends over time. Additionally, as shown in Table A7, regressions using quartiles both relax the OLS linearity assumption for $\beta$ and yield similar conclusions.

\section{Results}

By far, the largest effect of the voucher program is that it increased the depth of the donor pool. This finding is tied to the availability of vouchers. In 2017, the first year with Democracy Vouchers, donorship increased by $300 \%$ and in 2019, when they were next available, the participation rate in relation to 2017 nearly doubled (Seattle, 2020). However, these figures alone do not elucidate about who donates. This section assess the claim that voucher programs disrupt the donor pool status quo. Through a series of analyses, I find that this is not the case.

First, I present descriptive data on 2019 voucher users as well as 2015 cash donors. Wide disparities according to socioeconomic strata are seen in voucher participation. Figure 1 shows that 2019 voucher users are skewed toward groups already overrepresented in the previous cash-only donor pool when considering strata of income, ethnorace, age, past political participation, and party. Even among frequent voters, the rich participate disproportionately, a finding that is intuitive when donations are costly but not when donating is as free as voting. While these inequalities are stark, they are not inconsistent with the following process of voucher uptake: past donors continue to donate (many using vouchers in addition to or in lieu of cash), and those who were previously never-donors utilize vouchers with lower rates. Here, inequalities within the donor pool would persist, but would be lessened relative to prior years. The following difference-in-differences design assess this possibility. 
Figure 1 - Voucher uptake is highest among demographics known to participate most in local politics.
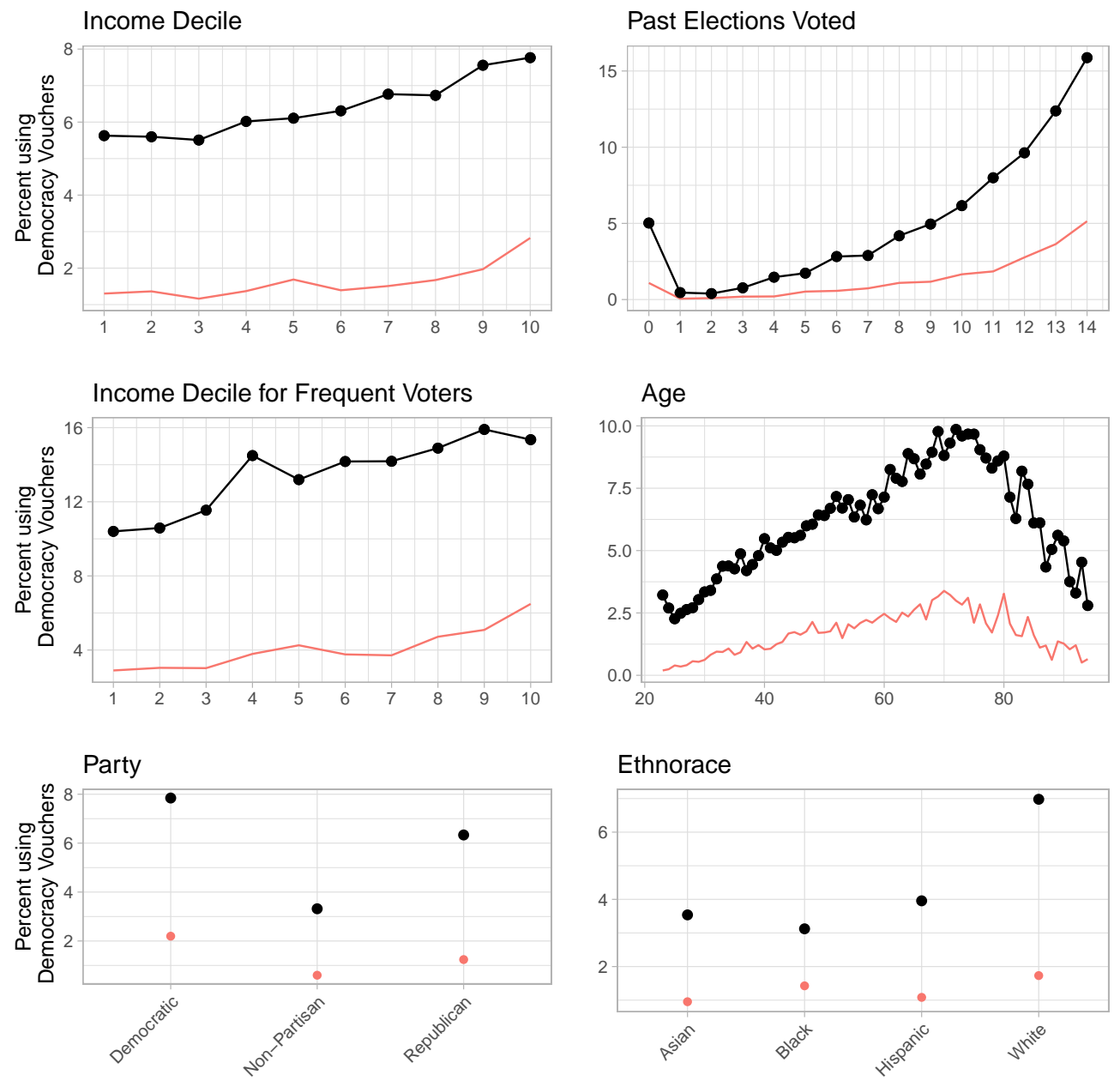

The data in black indicates voucher usage in 2019. For reference, data in red indicates cash participation in 2015 (which at the time, represented an all-time high in campaign finance participation). It is clear that the availability of vouchers drastically deepens the donor pool. The population utilized for these graphs is every Seattle registered voter present in both 2019 and 2015 voter files (258,519 citizens). As a group, this subset participates more than the population at large, but the patterns of participation remain similar. Figure A5 graphs 2019 voucher usage among the full 2019 population.

Table 2 shows the results of the difference-in-differences regressions outlined in Model 1. Cumulatively, these results suggest that the individuals most mobilized by the availability of Democracy Vouchers live in neighborhoods where participation has always been relatively high, whereas individuals whose costs to participating in campaign finance were most reduced by vouchers were comparatively less mobilized. Coefficients can be interpreted as follows. From Equation 1, a 1-unit increase in a block group mean voting level is associated with 
Table 2 - In Democracy Voucher years, campaign finance participation increases the most in census block groups with high levels of overrepresented characteristics.

\begin{tabular}{|c|c|c|c|c|}
\hline & \multicolumn{4}{|c|}{$\%$ Donating within Block Group } \\
\hline & $(1)$ & $(2)$ & $(3)$ & $(4)$ \\
\hline Voucher Program in Place*Mean Voting Index & $\begin{array}{c}0.85 \\
(0.09)\end{array}$ & & & \\
\hline Voucher Program in Place*\% White & & $\begin{array}{c}0.03 \\
(0.004)\end{array}$ & & \\
\hline Voucher Program in Place*Med Income & & & $\begin{array}{c}0.02 \\
(0.002)\end{array}$ & \\
\hline Voucher Program in Place*Conservative & & & & $\begin{array}{l}-2.24 \\
(0.39)\end{array}$ \\
\hline Observations & 3,808 & 3,808 & 3,808 & 3,304 \\
\hline Cycle FE & Yes & Yes & Yes & Yes \\
\hline Block Group FE & Yes & Yes & Yes & Yes \\
\hline
\end{tabular}

Each line is a block group-cycle. Mean Voting Index is the mean count of times voted in 14 federal elections (varying from 2.1 to 11.04 , with a mean of 9.1). Percent white ranges from $10.9 \%$ to $96.1 \%$, with a mean of $74.4 \%$. Median income is in thousands (ranging from 15.4 to 250 (data is right-truncated at 250), with a mean of 103). Conservative represents mean Bonica contributor CF Scores within each block group (ranging from -0.21 to -1.74 , with a mean of -1.1). Robust standard errors. Mean block group participation in voucher years is $6.45 \%$.

a $0.85 \%$ increase in campaign finance participation during voucher years for members of that block group, beyond already-existing time-invariant disparities. In Equation 2, a 1\% increase in white residents is associated with a $0.03 \%$ increase in voucher year participation. Equation 3 shows that a $\$ 1000$ jump in block group median income is associated with a $0.02 \%$ increase in participation in Democracy Voucher years. Equation 4 shows that a 1-unit increase in mean CF score is associated with a $2 \%$ decrease in participation in Democracy Voucher years.

Coefficients in Table 2 are small because of low rates of participation, even in years with vouchers. However, these differences are substantively significant. For exposition, consider the 2019 difference in new donors for two block groups that are 55\% and $75 \%$ white (groups A and B respectively) who have zero block fixed effects. In Equation 2, the 2019 fixed effect is $5.54 \%$. A is predicted to have $5.54+55^{*} 0.03=7.19$ new donors per 100 residents in voucher 
years, and $\mathrm{B}$ is predicted to have $5.54+75^{*} 0.03=7.79$. In 2019 , for every 100 new donors in A, B will have about 108 new donors. While the results in Table 2 rely on linearity in between the likelihood of donating and a block group's level of demographic attributes, Table 7 within the Appendix repeats this regression using quartiles, and confirms that these patterns are indeed monotonic.

Table 3 - Controlling for different attributes, individuals in overrepresented groups still benefit the most from the Democracy Voucher program.

\begin{tabular}{|c|c|c|c|c|c|c|c|}
\hline & \multicolumn{7}{|c|}{ Individual likelihood of donating (\%) } \\
\hline & $(1)$ & $(2)$ & $(3)$ & $(4)$ & $(5)$ & $(6)$ & $(7)$ \\
\hline VPP*White & $\begin{array}{c}1.90 \\
(0.08)\end{array}$ & & & $\begin{array}{c}0.37 \\
(0.09)\end{array}$ & & & \\
\hline VPP*Income Decile & & $\begin{array}{c}0.11 \\
(0.02)\end{array}$ & & $\begin{array}{c}0.11 \\
(0.02)\end{array}$ & & & \\
\hline VPP*Voting Index & & & $\begin{array}{c}0.86 \\
(0.01)\end{array}$ & $\begin{array}{c}0.87 \\
(0.01)\end{array}$ & & & \\
\hline $\mathrm{VPP}^{*}$ Age & & & & & $\begin{array}{c}0.06 \\
(0.004)\end{array}$ & $\begin{array}{c}-0.26 \\
(0.016)\end{array}$ & \\
\hline VPP*Republican & & & & & & & $\begin{array}{l}-2.39 \\
(0.13) \\
\end{array}$ \\
\hline Observations & $1,327,016$ & $1,239,904$ & $1,327,016$ & $1,239,904$ & $1,176,236$ & 150,016 & 959,656 \\
\hline Cycle FE & Yes & Yes & Yes & Yes & Yes & Yes & Yes \\
\hline Indiv FE & Yes & Yes & Yes & Yes & Yes & Yes & Yes \\
\hline Population & All & All & All & All & Under 71 & Over 70 & $\mathrm{D} / \mathrm{R}$ only \\
\hline
\end{tabular}

VPP $=$ Voucher Program in Place. Non-interacted terms are included within each model, but their output is suppressed. Votes is the count of times voted in 14 federal elections. Each line is an individual-cycle. Robust standard errors. The mean individual donation rate in voucher years is $6.75 \%$.

A limitation of Table 2 is that it is not necessarily clear who within a census block group has become mobilized in Democracy Voucher years. For example, while unlikely, the results from Table 2 could reflect high non-white and low white mobilization in predominantly nonwhite block groups, and high white mobilization in predominantly white block groups. Using L2's modelled race, income, and partisanship as well as age and an index of previous voting from administrative data, the results of Model 2 in Table 3 confirm the conclusions suggested by Table 2, that those becoming most mobilized to donate when donations are costless are the wealthy, white, retirement-aged, Democratic, and frequent voters. 
In Equation 1, a white individual has an additional 1.9\% higher likelihood of donating in a voucher year relative to a nonwhite individual. In Equation 2, a 1-decile increase in an individual's income decile is associated with a $0.11 \%$ increase in their voucher year participation likelihood. Equation 3 shows that voting in a single additional election is associated with a $0.86 \%$ increase in voucher year participation. These are each combined in Equation 4, and are all significant. Equation 5 (and 6) show that among individuals under 71 (over 70), each additional year is associated with a $0.06 \%(0.26 \%)$ increase (decrease) in voucher year participation. In Equation 7, relative to a Democrat, the increase in voucher year participation is $2.39 \%$ lower for Republicans.

Consider two individuals with zero fixed effects in the second (A) and ninth (B) income decile in 2019 , when the year fixed effect is $7.67 \%$. Of 100 people like A, $7.67+0.11 * 2=7.89$ are expected to become new donors when the voucher program is in place, in contrast to $7.67+0.11^{*} 9=8.66 \%$ for B. In other words, in 2019 , for ever 100 new donors just like A, there are 110 new donors just like B.

So far, I have shown that donors in voucher years are less representative of the citizenry than donors from previous years. However, this paper has not yet rejected the possibility that voucher users are more diverse, with movement towards donor pool diversity drowned out by non-diverse cash donors. Utilizing the constant Seattle resident panel, Figure 2 shows that the demographic breakdown of voucher users is typically similar to the demographic breakdown of both municipal as well as federal cash donors, both within-cycle and historically. In all cases except for income in $2017,{ }^{5}$ voucher users do not pull the municipal donor pool in more representative directions.

\footnotetext{
${ }^{5}$ Substitution may be the driving mechanism in 2017's case. Consider the population of 2015 donors, who are among the most likely to donate in 2017. Among both the highest and lowest income decile, nonparticipation rates are identical at $71.6 \%$ and $71.7 \%$, respectively. However, voucher-only usage is higher among the lowest decile, with $44.4 \%$ (relative to $26.9 \%$ ) of 2015-2017 donors utilizing only vouchers in 2017. That is, high-propensity donors will similarly participate in voucher years, but high-propensity high-income donors will still contribute cash (often in addition to vouchers) while high-propensity low-income donors have a higher tendency to make voucher-only contributions.
} 
Figure 2 - The composition of voucher users rarely differ from the composition of cash donors within-year or over-time.
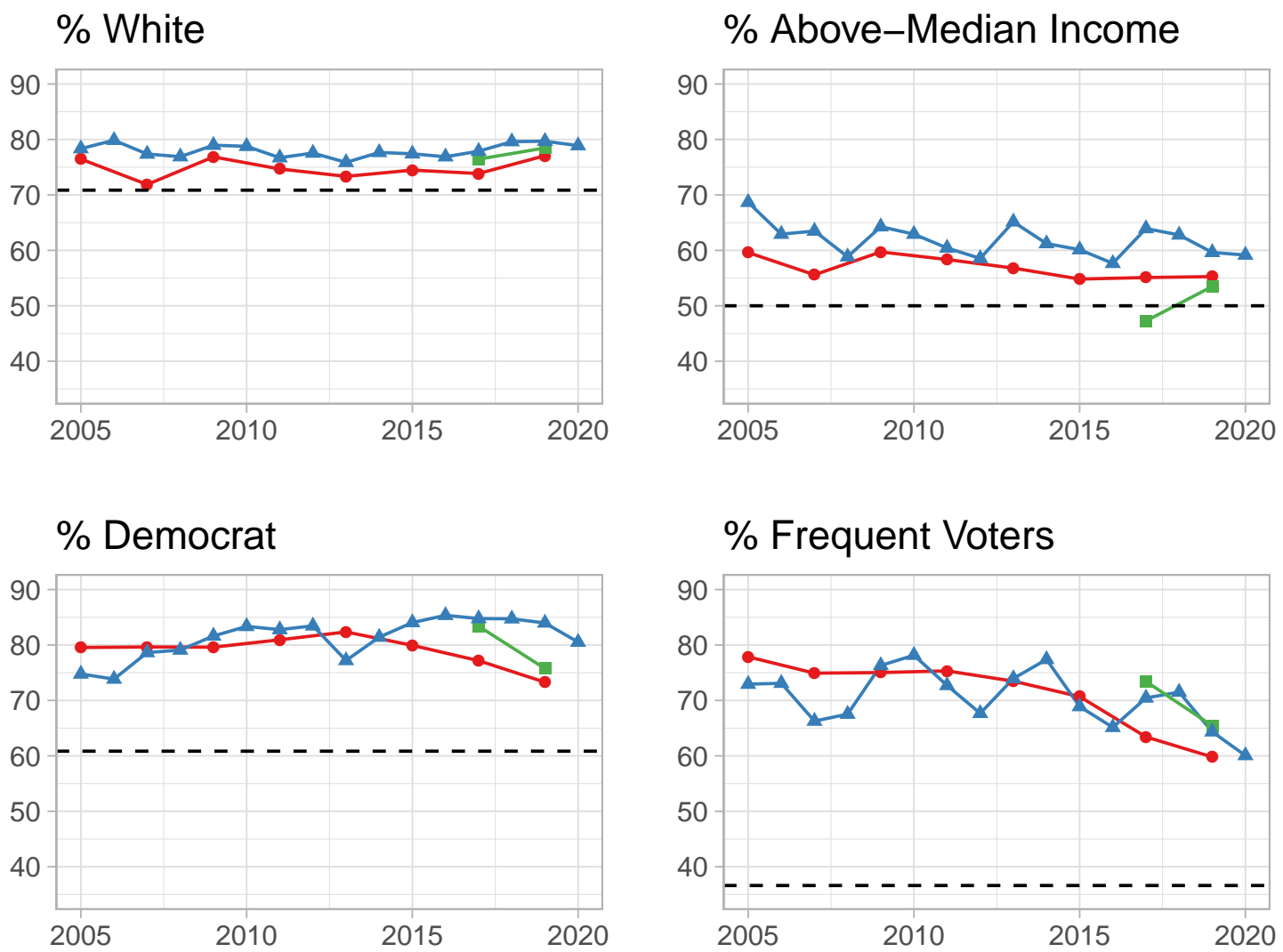

source $\rightarrow$ Muni cash $\_$Federal cash $\rightarrow-$ Voucher

Dashed lines represent population parity. This figure is replicated in Figure A4 utilizing dollar-weighted donations.

\section{Discussion}

Without further changes, the availability of Democracy Vouchers themselves appears to follow patterns similar what was found in the proliferation of vote-by-mail in Oregon in Berinsky et al. (2001) and Berinsky (2005): participation in campaign finance increases primarily through those who had the highest propensities to donate even prior to reform. In 2019 with campaign finance participation at an all-time high, groups with the lowest propensities to participate were still not mobilized by campaign finance reform: about $2.5 \%$ of Blacks, $3 \%$ of non-partisans, $2 \%$ of those in their mid-twenties, and less than $1 \%$ of 
almost-never-voters participated. In contrast, whites and Democrats participated at double the rate, retirement-age individuals at nearly triple the rate, and frequent voters at over 15 times the rate, respectively. Even among frequent voters, those with the highest incomes participated $47 \%$ more often than those with the lowest incomes, and white frequent voters participated 50\% more than African-American frequent voters (see Figures A5 and A6). In sum, vouchers rarely mobilize low-propensity participants, and usage is uneven across strata even for high-propensity participants. In this section, I discuss two potential mechanisms for mobilization and conclude.

There is evidence that the market for donations may be structured by who runs. Within Seattle's municipal elections, nonwhite and intersectional individuals donate more to nonwhite and intersectional candidates (see Table A5). While candidates who opt into public financing are similar to pre-voucher candidates on dimensions of race (see Tables A4 and A6 and Figure A2), victorious publicly-financed candidates tend to be less wealthy but also more liberal. On average, their donors are less wealthy and equally white and liberal (though more polarized on both sides). In sum, voucher-accepting candidates are somewhat different from other candidates, and their donors similarly differ. The donor pool may eventually diversify through changes to the candidate pool, though it is not assured that public financing alone will successfully bring about changes to the candidate pool (Kilborn, 2018, La Raja and Wiltse, 2015).

As the Democracy Voucher program is new, disproportionate participation may be driven by asymmetric knowledge. Reports from both 2017 and 2019 commissioned by the city of Seattle indicated that even in 2019, only about half of those surveyed were familiar with the program (BERKS Consulting, 2018, BERKS Consulting, 2020). Though both the samples are underpowered for subgroup analyses, pooling together non-white individuals suggests that knowledge about the Democracy Voucher program was highest among whites and the wealthy in 2019, though higher familiarity among people of color, equal to that of 
whites, was reported in 2017. However, this is unlikely to be a primary cause of the disparity: knowledge of Democracy Vouchers is likely associated with an individual's voting history, and disparities continue to exist even within frequent-voters (Figure A6).

\section{Conclusion}

While Seattle's Democracy Voucher program is still nascent, federal and local policymakers are advocating for the adoption of similar campaign finance reforms. Proponents claim that voucher-style reforms will transform campaign finance participation to become more representative of the proverbial "people." Using administrative data, I find that Seattle's Democracy Voucher program, the first in the nation to fully drag the monetary costs of political donations to zero, does not drastically alter the composition of the donor pool. Most notably, frequent voters with low incomes, who may have previously been priced out of the campaign finance process, still contributed much less frequently than frequent voters with medium and high incomes. The participation of individuals in non-dominant groups in Seattle politics, such as the young, non-white, and conservatives, increased at significantly lower rates than those of groups dominant in Seattle politics. While the donor pool expanded, vouchers increased the gap between the donor pool and the citizenry.

Though Seattle's voucher program has not produced a donor pool that mirrors the citizenry, there are additional issues that campaign finance reforms aim to address. Alongside vouchers came a larger donor pool, a deeper candidate pool, lower levels of wealth for elected candidates, higher fundraising totals for candidates, and a decrease in reliance on large and corporate donors, though whether these are causally attributable to vouchers instead of other campaign finance and electoral reforms is not clear. While some of these attributes found within Seattle's voucher year elections have been discussed within past research in areas without vouchers (e.g. Abott and Magazinnik, 2020, Gulzar et al., 2020, Malhotra, 2008, Trounstine and Valdini, 2008), an examination of whether vouchers are causally responsible 
for these attributes, as well as further study on the electoral consequences of these attributes provide directions for future work on campaign finance in local elections. 


\section{References}

117th Congress. (2021). H.R. 1: An act. https ://www . congress .gov/117/bills/hr1/ BILLS-117hr1eh $\cdot$ pdf\#page $=622$

Abott, C., \& Magazinnik, A. (2020). At-Large Elections and Minority Representation in Local Government. American Journal of Political Science, 64(3), 717-733.

Alvarez, M., Bailey, D., \& Katz, J. N. (2008). The effect of voter identification laws on turnout. http://ssrn.com/abstract $=1084598$

Angrist, J. D., \& Pischke, J. (2008). Mostly harmless econometrics: An empiricist's companion. Princeton University Press.

Anzia, S. F. (2011). Election timing and the electoral influence of interest groups. The Journal of Politics, $73(2), 412-427$.

Anzia, S. F., \& Berry, C. R. (2011). The Jackie (and Jill) Robinson effect: Why do congresswomen outperform congressmen? American Journal of Political Science, 55(3), $478-493$.

Atkeson, L. R., Bryant, L. A., Hall, T. E., Saunders, K., \& Alvarez, M. (2010). A new barrier to participation: Heterogeneous application of voter identification policies. Electoral Studies, 29(1), 66-73.

Banducci, S. A., Donovan, T., \& Karp, J. A. (2004). Minority representation, empowerment, and participation. $66(2), 534-556$.

Barber, M. J., Butler, D. M., \& Preece, J. (2016). Gender inequalities in Campaign Finance. Quarterly Journal of Political Science, 11(2), 219-248.

Barber, M. J., Canes-Wrone, B., \& Thrower, S. (2017). Ideologically sophisticated donors: Which candidates do individual contributors finance? American Journal of Political Science, 61(2), 271-288.

Berinsky, A. J. (2005). The perverse consequences of electoral reform in the United States. American Politics Research, 33(4), 471-491. 
Berinsky, A. J., Burns, N., \& Traugott, M. W. (2001). Who votes by mail? A dynamic model of the individual-level consequences of voting-by-mail systems. Public Opinion Quarterly, 65(2), 178-197.

BERKS Consulting. (2018). 2017 Election cycle evaluation. http://www . seattle .gov/ Documents/Departments/EthicsElections/DemocracyVoucher/DVP\%5C\%20Evaluation\% 5C $\% 20$ Final $\% 5 C \% 20$ Report $\% 5 C \% 20$ April $\% 5 C \% 2025 \% 5 C \% 202018$.pdf

BERKS Consulting. (2020). 2019 Election cycle evaluation. http://www . seattle .gov/ Documents/Departments/EthicsElections/DemocracyVoucher/Final \%5C\%20DVP\% 5C\%20Evaluation\%5C\%20Report\%5C\%20July23_2020.pdf

Bonica, A. (2014). Mapping the ideological marketplace. American Journal of Political Science, $58(2), 367-386$.

Bonica, A. (2016). Database on ideology, money in politics, and elections: Public version 2.0. https://data.stanford.edu/dime

Bonica, A., Grumbach, J. M., Hill, C., \& Jefferson, H. (2021). All-mail voting in Colorado increases turnout and reduces turnout inequality. Electoral Studies, 72, 102363.

Brady, H. E., Verba, S., \& Lehman Schlozman, K. A. Y. (1995). Beyond SES: A resource model of political participation. The American Political Science Review, 89(2), 271294.

Broockman, D., \& Malhotra, N. (2020). What do partisan donors want? Public Opinion Quarterly, 84(1), 104-118.

Chattopadhyay, R., \& Duflo, E. (2004). Women as policy makers: Evidence from a randomized policy experiment in India. Econometrica, 72(5), 1409-1443.

Gerber, A. S., Huber, G. A., \& Hill, S. J. (2013). Identifying the effect of all-mail elections on turnout: Staggered reform in the evergreen state. Political Science Research and Methods, 1(1), 91-116.

Gilens, M. (2009). Preference gaps and inequality in representation. PS - Political Science and Politics, 42(2), 335-341. 
Gillibrand, K. (2019). Getting money out of politics. https ://medium.com/team-gillibrand/ my-clean-elections-plan-to-get-money-out-of-politics-ba02ec1aaf 19

Grimmer, J., Hersh, E., Meredith, M., Mummolo, J., \& Nall, C. (2018). Obstacles to estimating voter ID laws' effect on turnout. Journal of Politics, 80(3), 1045-1051.

Grumbach, J. M., \& Sahn, A. (2019). Race and representation in campaign finance. American Political Science Review, 206-221.

Grumbach, J. M., Sahn, A., \& Staszak, S. (2020). Gender, race, and intersectionality in campaign finance. Political Behavior, 1-22.

Gulzar, S., Rueda, M. R., \& Ruiz, N. A. (2020). Do campaign contribution limits curb the influence of money in politics?

Hajnal, Z., Lajevardi, N., \& Nielson, L. (2017). Voter identification laws and the suppression of minority votes. Journal of Politics, 79(2), 363-379.

Hajnal, Z., \& Trounstine, J. (2005). Where turnout matters: The consequences of uneven turnout in city politics. The Journal of Politics, 67(2), 515-535.

Henderson, G., \& Han, H. (2021). If we build it, only some will come: An experimental study of mobilization for Seattle's Democracy Voucher program. Journal of Experimental Political Science, 1-16.

Hopkins, D. J., Meredith, M., Chainani, A., Olin, N., \& Tse, T. (2021). Results from a 2020 field experiment encouraging voting by mail. https : / / doi .org/10 .1073/pnas $.2021022118 /$

Ingalls, G. L., \& Arrington, T. S. (1991). The role of gender in local campaign financing: The case of Charlotte, North Carolina. Women and Politics, 11(2), 61-89.

Kalla, J. L., \& Broockman, D. E. (2016). Campaign contributions facilitate access to congressional officials: A randomized field experiment. American Journal of Political Science, $60(3), 545-558$. 
Kilborn, M. (2018). Public campaign financing, candidate socioeconomic diversity, and representational inequality at the U.S. state level: Evidence from Connecticut. State Politics and Policy Quarterly, 18(3), 296-323.

Kogan, V., Lavertu, S., \& Peskowitz, Z. (2018). Election timing, electorate composition, and policy outcomes: Evidence from school districts. American Journal of Political Science, 62(3), 637-651.

Kousser, T., \& Mullin, M. (2007). Does voting by mail increase participation? Using matching to analyze a natural experiment. Political Analysis, 428-445.

La Raja, R. J., \& Wiltse, D. L. (2015). Money that draws no interest: Public financing of legislative elections and candidate emergence. Election Law Journal, 14(4), 392-410.

Lueders, H., Hainmueller, J., \& Lawrence, D. (2017). Providing driver's licenses to unauthorized immigrants in California improves traffic safety. Proceedings of the National Academy of Sciences, 114(16), 4111-4116.

Malhotra, N. (2008). The impact of public financing on electoral competition: Evidence from Arizona and Maine. State Politics 83 Policy Quarterly, 8(3), 263-281.

McCabe, B. J., \& Heerwig, J. A. (2019). Diversifying the donor pool: How did Seattle's Democracy Voucher program reshape participation in municipal campaign finance? Election Law Journal: Rules, Politics, and Policy, 18(4), 323-341.

Oliver, J. E., \& Ha, S. E. (2007). Vote choice in suburban elections. American Political Science Review, $101(3), 393-408$.

Overton, S. (2004). The donor class: Campaign finance, democracy, and participation.

Pantoja, A. D., \& Segura, G. M. (2003). Does ethnicity matter? Descriptive representation in legislatures and political alienation among Latinos. Social Science Quarterly, 84(2), $441-460$.

Sanders, B. (2020). Get corporate money out of politics. https://berniesanders .com/ issues/money-out-of-politics/ 
Seattle. (2020). 2019 Biennial report. https : //www . seattle .gov/democracyvoucher / program-data/internal-program-reports

Tam Cho, W. K. (2002). Tapping motives and dynamics behind campaign contributions: Insights from the Asian American case. American Politics Research, 30(4), 347-383.

Thompson, D. M., \& Nowacki, T. (2021). Do elections increase local policy responsiveness? Evidence from elected police commissioners.

Thomsen, D. M., \& Swers, M. L. (2017). Which women can run? Gender, partisanship, and candidate donor networks. Political Research Quarterly, 70 (2), 449-463.

Trounstine, J., \& Valdini, M. E. (2008). The context matters: The effects of single-member versus at-large districts on city council diversity. American Journal of Political Science, 52(3), 554-569.

Wu, J., Yorgason, C., Folsz, H., Handan-Nader, C., Myers, A., Nowacki, T., Thompson, D. M., Yoder, J., \& Hall, A. B. (2020). Are dead people voting by mail? Evidence from Washington state administrative records.

Yang, A. (2020). Democracy dollars - Andrew Yang for president. https ://www · yang2020 .com/policies/democracydollars/ 


\section{Appendix}

\subsection{Data Related}

\subsubsection{Elections used to construct Voting Index}

The following elections were used to construct the voting index. They consist of congressional primaries as well as general elections in even-years. These elections are among those with the highest levels of turnout in Washington. Presidential primaries are excluded for two reasons. First, presidential primaries often had no meaningful Democratic competition, as there was a sitting incumbent. This is important, as most Seattle residents vote Democratic in national elections. Additionally, many presidential primaries were caucuses, which have extraordinarily low participation and their records are not retained by the Secratary of State.

Table 1 - Elections counted to construct the voting index

\begin{tabular}{l}
\hline Election Date \\
\hline November 6, 2018 \\
August 7, 2018 \\
November 8, 2016 \\
August 2, 2016 \\
November 4, 2014 \\
August 5, 2014 \\
November 6, 2012 \\
August 7, 2012 \\
November 2, 2010 \\
August 17, 2010 \\
November 4, 2008 \\
August 19, 2008 \\
November 7, 2006 \\
September 19, 2006 \\
\hline \hline
\end{tabular}

\subsubsection{Name matching procedure}

This subsection addresses matching in between the voter file and SEEC data, where the only link is names (single string from SEEC and first/last/middle in separate fields within the voter file), zip code, and voter file version/date donated. All matches required voter file 
year to be the same as year donated and that zip codes matched. An iterative procedure is used to address matching based on names. Those not matched using single-string full names (with or without middle initials) had their names split up according to the number of spaces within the name string and matched alongside other names with the same number of strings. All procedures involve matching both a possible first name and possible last name to the voter file. The following table shows all procedures used. Only one-to-one matches are considered: if a single SEEC line yields multiple records in the voter file, the match is rejected.

\begin{tabular}{llll}
\hline \hline Spaces & {$[\mathbf{a}, \mathbf{b}]$} & {$[\mathbf{a}, \mathbf{b}, \mathbf{c}]$} & {$[\mathbf{a}, \mathbf{b}, \mathbf{c}, \mathbf{d}]$} \\
\hline Proc 1 & {$[\mathrm{a}, \mathrm{b}]$} & {$[\mathrm{a}, \mathrm{c}]$} & {$[\mathrm{a}, \mathrm{d}]$} \\
Proc 2 & & {$[\mathrm{a}, \mathrm{b}]$} & {$[\mathrm{ab}, \mathrm{d}]$} \\
Proc 3 & & {$[\mathrm{ab}, \mathrm{c}]$} & {$[\mathrm{ab}, \mathrm{cd}]$} \\
Proc 4 & & {$[\mathrm{a}, \mathrm{bc}]$} & {$[\mathrm{a}, \mathrm{bcd}]$} \\
\hline \hline
\end{tabular}

Table 2 - An example of a match procedure for the hypothetical MARY KATE OLSON, who donated cash as MARY KATE OLSON but is registered to vote as [MARY, K, OLSON]. First, "MARY KATE OLSON" == "MARY K OLSON" and "MARY OLSON" are tried and both fail. Next, the string "MARY KATE OLSON" from the SEEC data is deconcatenated by white space into [MARY, KATE, OLSON], and I try to match the first name-last name pair [MARY, OLSON] from the voter file. The first procedure then tries to match $[\mathrm{a}, \mathrm{c}]=[\mathrm{MARY}$, OLSON] to $[\mathrm{MARY}$, OLSON], which is indeed a match. Assuming that this is the only MARY OLSON within the zip code-year, this match succeeds and MARY KATE OLSON is removed from the pool of names to continue onto subsequent matching procedures. Procedures such as [a,bcd] indicate concatenating the non-comma-separated letters, for example, for procedure [a,bcd], "SERENA VAN DER WOODSEN" in the SEEC data (three spaces) gets searched as [SERENA, VANDERWOODSEN] and procedure [ab,d] is searched as [SERENAVAN, WOODSEN].

\subsubsection{Matching with name and address}

CF Scores: Individual CF Ideology Scores from Bonica (2016) are matched onto voter file data based on first name, last name, gender, a standardized first line of an address, and zip code. This level of an exact match is possible because of the high level of data cleaning conducted by Bonica within the DIME database. 
FEC data: FEC data is not necessarily clean. Nicknames, misspellings, and especially inconsistent addresses are common. FEC data was downloaded from https://www.fec.gov/ data/receipts/individual-contributions/?contributor_city=Seattle\&contributor_state= WA, consisting of donations only from Seattle, WA, to authorized committees of House, Senate, and presidential candidates from 2005-2020. These were matched to the voter file using full name (split first and last name are not available) and zip code. 


\subsection{L2's demographic predictions against known data}

Estimates of individual data from vendors is often described as a "black box", where it's unclear how values are calculated and whether these values are accurate. Because some of my central findings are strengthened by vendor estimates of income, I validate these measures by comparing data from L2 to their true values.

\begin{tabular}{lllr}
\hline $\begin{array}{c}\text { SEEC } \\
\text { DOLLAR } \\
\text { CODE }\end{array}$ & \multicolumn{3}{c}{ AMOUNT } \\
(1) & $\$ 0$ & - & $\$ 999$ \\
(2) & $\$ 1,000$ &.- & $\$ 4,999$ \\
(3) & $\$ 5,000$ &.- & $\$ 9,999$ \\
(4) & $\$ 10,000$ &.- & $\$ 24,999$ \\
(5) & $\$ 25,000$ & - & $\$ 99,999$ \\
(6) & $\$ 100,000$ &.- & $\$ 199,999$ \\
(7) & $\$ 200,000$ &.- & $\$ 999,999$ \\
(8) & $\$ 1,000,000$ &.- & $\$ 4,999,999$ \\
(9) & $\$ 5,000,000$ & or more
\end{tabular}

Figure 1 - SEEC dollar codes from an F-1 Personal Fiancial Affairs Statement, which is a necessary filing for candidates in 2017 and 2019 elections for city council and city attorney.

\subsubsection{Income against administrative data}

Table 3 - Binned income esimates are generally close to true binned income estimates

\begin{tabular}{lc}
\hline \hline & \multicolumn{2}{c}{ Dependent variable: } \\
\cline { 2 - 2 } & L2 estimated income (binned) \\
\hline Self reported income bin & $1.029^{* * *}$ \\
& $(0.026)$ \\
\hline Observations & 51 \\
$\mathrm{R}^{2}$ & 0.969 \\
Adjusted $\mathrm{R}^{2}$ & 0.968 \\
Residual Std. Error & 1.055 \\
F Statistic & $1,563.450^{* * *}$ \\
\hline \hline Note: & ${ }^{*} \mathrm{p}<0.1 ;{ }^{* *} \mathrm{p}<0.05 ;{ }^{* * *} \mathrm{p}<0.01$
\end{tabular}

In this regression, an intercept of 0 is forced. This model shows that L2 estimated incomes are indeed accurate representations of an individual's true income, with an $R^{2}$ value of 0.97. Error is largely driven by four points: two with very low self-reported incomes 
with medium L2 estimated incomes, and two with high self-reported income alongside low estimated incomes. ${ }^{6}$ Of course a limitation in this regression is that incomes are binned, leaving less room to confidently run analysis with the raw values of L2 estimated incomes. For this reason, in my analysis using incomes, I bin L2-estimated incomes into deciles.

\subsubsection{Imputed race against hand-coded race}

This section presents a confusion matrix, pitting L2-estimated race against hand-coded race for city council and city attorney candidates. Hand coding involved searching the internet for websites and photos of candidates. True Values are on the rows and modeled values are in the columns. Not all individuals are categorized by L2, partially due to the fact that I only have newer L2 files from 2017 and beyond (therefore, if a candidate left Seattle in 2009, I wouldn't have their L2 data), and also because L2 is not able to categorize all individuals into a racial group. These facts explain the sparseness of the table.

\begin{tabular}{rrrrr}
\hline \hline & Asian & Black & Hispanic & White \\
\hline Asian & 4 & 0 & 0 & 1 \\
Black & 0 & 2 & 0 & 4 \\
Hispanic & 0 & 0 & 11 & 1 \\
White & 3 & 0 & 0 & 59 \\
\hline \hline
\end{tabular}

Only $57 \%$ of imputed Asians are really Asian (however, it is worth noting, this error is largely due to two female candidates in interracial marriages who adopted the last name of their Asian spouses: Daniela Lipscomb-Eng and Heidi Wills (who is registered to vote as Heidi Yamada)). The L2 algorithm struggles with correctly classifying Blacks. While everyone it imputes as Black is indeed Black, it misses $67 \%$ of individuals who are actually Black. Consistent with the in-text discussion about race-imputation methods, significant

\footnotetext{
${ }^{6}$ Among the former is an individual who clearly hastily filled out the F-1 financial affairs disclosure, and purports that their income is from "SS" (likely Social Security) amounts to less than $\$ 1000$ a month, well below the average Social Security benefit. He additionally circled the "5" in the legend section that corresponds dollar amounts with bins, perhaps indicating that 5 (which is in line with maximum social security benefits for individuals retiring at 62 or older). The second within the former group is an individual who reports a household income of less than $\$ 5000$ but a net worth of $\$ 900,000$.
} 
error comes from misclassifying POC as white. L2 fares better with Hispanics, correctly categorizing $92 \%$ as Hispanic and incorrectly categorizing one as white.

\subsubsection{L2 Partisan estimates}

Washington does not record party information. L2 states the following: "For the most part, the Washington State parties have run their presidential nominating processes by caucus rather than by presidential primary. However, during the presidential cycles of 1992, 1996, 2000, 2008 and 2016, the state also ran presidential primaries. In each of these presidential primaries, the state temporarily recorded the party ballot that was picked up by each voter. However, they destroyed that information within a couple of months after each primary. L2 acquired all of it after each primary when it was still available and I believe we are the only source for this information. We were told when we were gathering it that no one else, including the parties, was asking for it. Since this is self-reported party affiliation and turnout in these presidential primaries was high, it is both very accurate and has good coverage. The information that the parties themselves have for their caucus attendees pales in comparison since participation in those caucuses is so low. For those that did not

participate in one or more of these presidential primaries, we used sophisticated modeling techniques along with our information about the party affiliation of the candidates to whom voters provided federal contributions." 


\subsection{Candidate-Level Data}

Participation in the Democracy Voucher program enables candidates to collect funds from donors while costing donors nothing. Though participation limits candidates' ability to raise large dollar donations (reducing maximum individual cash donations from $\$ 550$ to $\$ 300)$ candidates can raise up to $\$ 300,000$ in vouchers. Contingent upon achieving the qualifications needed to participate within the Democracy Voucher program ${ }^{7}$ (largely administrative tasks plus $400 \$ 10$ or higher cash donations and signatures for at-large city council and city attorney seats, and $150 \$ 10$ donations and signatures for district city council seats), participation in the Democracy Voucher program among candidates is high. Of the fourteen city council candidates who made it to the general election in 2019, all but two participated in the Democracy Voucher program. Of the six city council and city attorney candidates within the 2017 general election, all but one participated. Those choosing to not participate are generally well-known or well-off: of these three viable (loosely defined) candidates who refused participation, one, Councilmember Sawant, is a highly controversial incumbent whose 2019 and 2015 campaigns were two most expensive in Seattle City Council history (in particular, she feared being outspent by Amazon, a corporate tenant within her district), and the other two had self-reported net worths of over $\$ 800,000$. Among these, only the incumbent won their race.

\subsubsection{Data sources}

For candidate demographics, the voter file was merged along with a list of candidates from 2005-2019. Candidates include only those who stayed within races until at least the primary election, and names and election-level information are obtained from Seattle's cam-

\footnotetext{
${ }^{7}$ Detailed qualifications for participation are outlined here: http://www.seattle.gov/democracyvoucher/ i-am-a-candidate
} 
paigns archive. ${ }^{8}$ Candidate ideology scores are computed utilizing Bonica CF score data, described below. Data on candidate wealth is described in a previous section.

\subsubsection{Merging procedure}

Because there are few candidates and subsequently little room for error in calculating candidate demographics, candidates are hand-matched to records from the voter file. In ambiguous cases (such as when a candidate has a common name or a nickname), candidate information from news articles, candidate websites, or other publicly accessible administrative data are utilized to match individuals to the most likely individual within the voter file. $^{9}$

\subsubsection{CF scores procedure}

Ideology scores are computed for City Council and City Attorney candidates utilizing Bonica, 2014 individual campaign finance data. Using the individual donor files from 2008, 2010, 2012, and 2014, I merged individual CF scores to the voter file based on an exact first name, last name, gender, zip, and modified street address. ${ }^{10}$ Once the Seattle resident voter file contained CF scores for individuals, I merged this voter file with the donations dataset. For each candidate, their CF score is the average of the individual CF scores associated the candidate's received cash donations, not weighted by contribution amount. In sum, in order to be included in the candidate CF score calculation, an individual must first have donated to a race that enters into the DIME database (mostly federal races), then this individual must also have donated cash to a candidate for Seattle City Council or City Attorney in

\footnotetext{
8http://web6.seattle.gov/ethics/elections/campaigns.aspx for campaign finance numbers, https://www.seattle.gov/cityarchives/seattle-facts/historical-election-results for general election results, https://www.kingcounty.gov/depts/elections/elections/past-elections.aspx for primaries where easier-to-access statistics were unavailable (generally earlier years)

${ }^{9}$ Two common methods of matching common names include utilizing candidate media to find the name of their spouse and to select the voter file where a matching shared address exists, as well as matching zip code to the city council district (after the transition from at-large seats to single-member districts).

${ }^{10}$ Because the city of Seattle consists of many apartment dwellers, I sought to standardize the many ways to represent an apartment address. All of "Ste.," "\#," "Apt," and "Unit" were temporarily replaced and matched to "Apt" within both datasets.
} 
2005-2019. Then, their voter file names, gender, and address have to match those within DIME. Within each of these steps, this individual has to unambiguously be the donor: all name-zip duplicates are dropped to reduce false matches.

Of 156 unique candidates, 135 are have a calculated CF score, though 23 of these are subsequently dropped because they are matched to fewer than five donations associated with a CF score. 


\section{Mechanisms for persisting inequality}

\subsection{Comparison of candidate attributes, stratified by public fi- nancing participation}

Table 4 - Voucher candidates and winners are statistically more representative of the full population on dimensions of income. While CF scores are significant for elected candidates, the movement is in a less representative direction.

\begin{tabular}{rrrrrrr}
\hline \hline & \multicolumn{3}{c}{ Candidate } & & \multicolumn{3}{c}{ Elected } & \\
\cline { 2 - 3 } \cline { 5 - 6 } & No voucher & Voucher & SE & No voucher & Voucher & SE \\
\hline Income & 150.13 & 132.04 & 12.20 & 173.92 & 118.02 & 18.61 \\
Female & 0.37 & 0.44 & 0.09 & 0.43 & 0.55 & 0.18 \\
Nonwhite & 0.17 & 0.29 & 0.08 & 0.26 & 0.36 & 0.17 \\
Age & 49.78 & 46.15 & 2.19 & 54.44 & 46.55 & 4.05 \\
Cash CF Score & -0.97 & -1.08 & 0.09 & -1.09 & -1.21 & 0.05 \\
$\mathrm{~N}$ & 117 & 41 & & 35 & 11 & \\
\hline \hline
\end{tabular}

Candidates who were not able to have CF scores computed for them due to having five or fewer cash donations are dropped. A description of candidate-level data is available in Section 1.3 of the Appendix.

\subsection{Donors give more often to in-group candidates}

Table 5 - In 2019, in-group individuals donate substantially more to in-group candidates.

\begin{tabular}{rrr}
\hline \hline & Voucher & Cash \\
\hline Donations to nonwhite candidates & & \\
Nonwhite donors & 0.33 & 0.36 \\
White donors & 0.26 & 0.24 \\
Standard Error & 0.01 & 0.01 \\
Donations to female candidates & & \\
Female donors & 0.48 & 0.44 \\
Male donors & 0.40 & 0.33 \\
Standard Error & 0.00 & 0.01 \\
Donations to intersectional candidates & & \\
Inersectional donors & 0.28 & 0.34 \\
Non-Intersect donors & 0.22 & 0.20 \\
Standard Error & 0.01 & 0.02 \\
\hline \hline
\end{tabular}

Numbers represent the proportion of donations within a group made to a certain candidate. For example, $33 \%$ of voucher donations made from nonwhite donors go to nonwhite candidates, while $26 \%$ of voucher contributions from white donors go to nonwhite candidates, and the standard error for this difference is $2 \%$. This table subsets to candidates who accepted both cash and voucher contributions. Standard errors generated using Welch t-tests. 


\subsection{Do donors to publicly financed candidates differ?}

Table 6 - Donors for voucher-accepting candidates and cash-only candidates sometimes differ

\begin{tabular}{rrrr}
\hline \hline & Voucher-accepting & Cash-only & SE \\
\hline \% Democrat & 0.75 & 0.81 & 0.024 \\
Income Decile & 5.84 & 6.33 & 0.16 \\
\% White & 0.78 & 0.75 & 0.012 \\
\hline \hline
\end{tabular}

Standard errors represent Welch two-sample t-test standard errors. The unit of analysis is each candidate with over 200 matched donors.
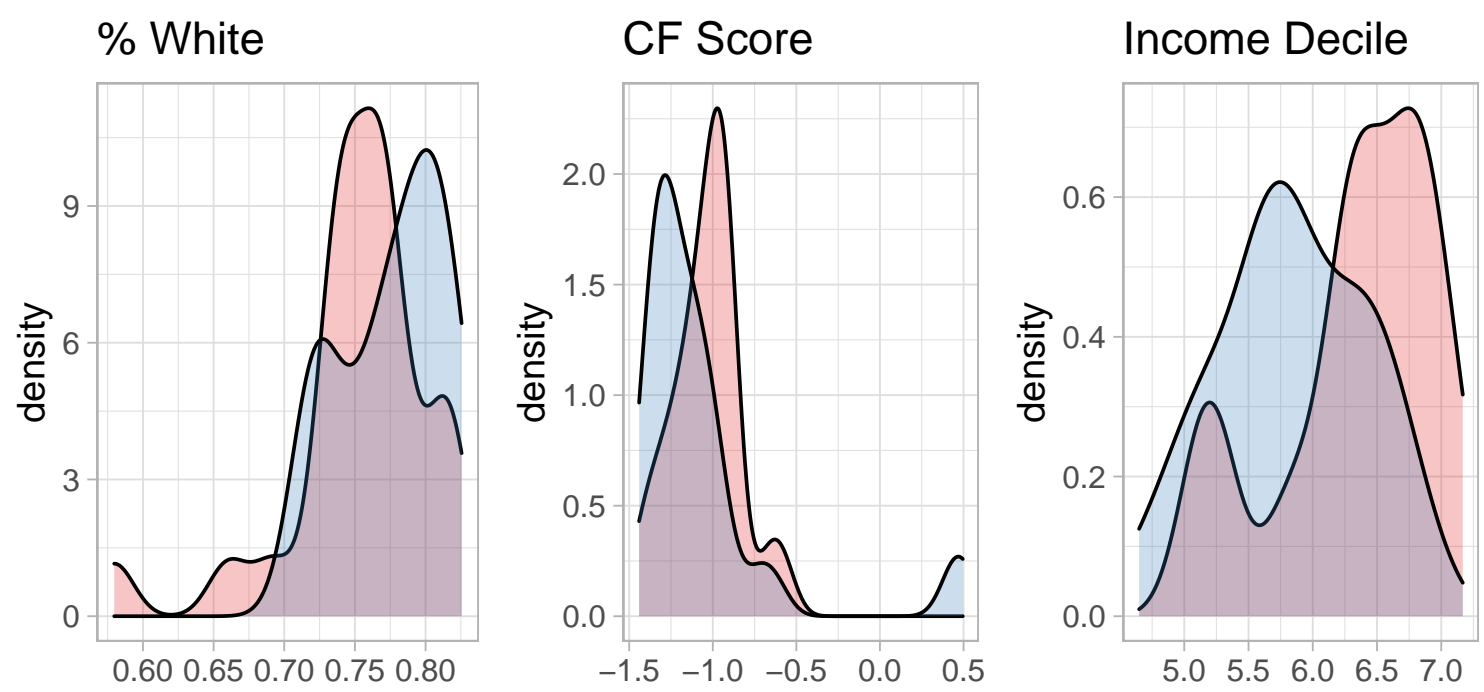

Figure 2 - Publicly-financed candidates are more likely to have higher white support, more polarizing ideologies, and less-wealthy donors. Blue masses represent the distribution of average donors for voucher candidates (cash-only candidates in red). The unit of analysis is each candidate with over 200 matched donors. That is, candidates represented in red represent candidates spanning the whole 2005-2019 time span, while voucher candidates necessarily are from 2017 or 2019 . While this may appear to suggest that vouchers promote donor diversity, this is a very limited analysis. First, the pooling of years masks the fact that even the cash donor pools have become more representative over time (the pooling is unavoidable as a vast majority of successful 2017 and 2019 candidates opted into public financing). Second, these analyses are weighted by candidate, not by candidate popularity. For example, the most donated-to cash-only candidate, Councilmember Sawant, has an average donor decile of 5.2, while the most donated-to voucher candidates have average donor deciles of 5.6, 5.9, 5.6. Some may argue that Sawant's candidacy is a special case. Results from this analysis are not substantively different with her exclusion. 


\section{Block group parallel trends and model results}

\subsection{Parallel trends for block group quartiles}
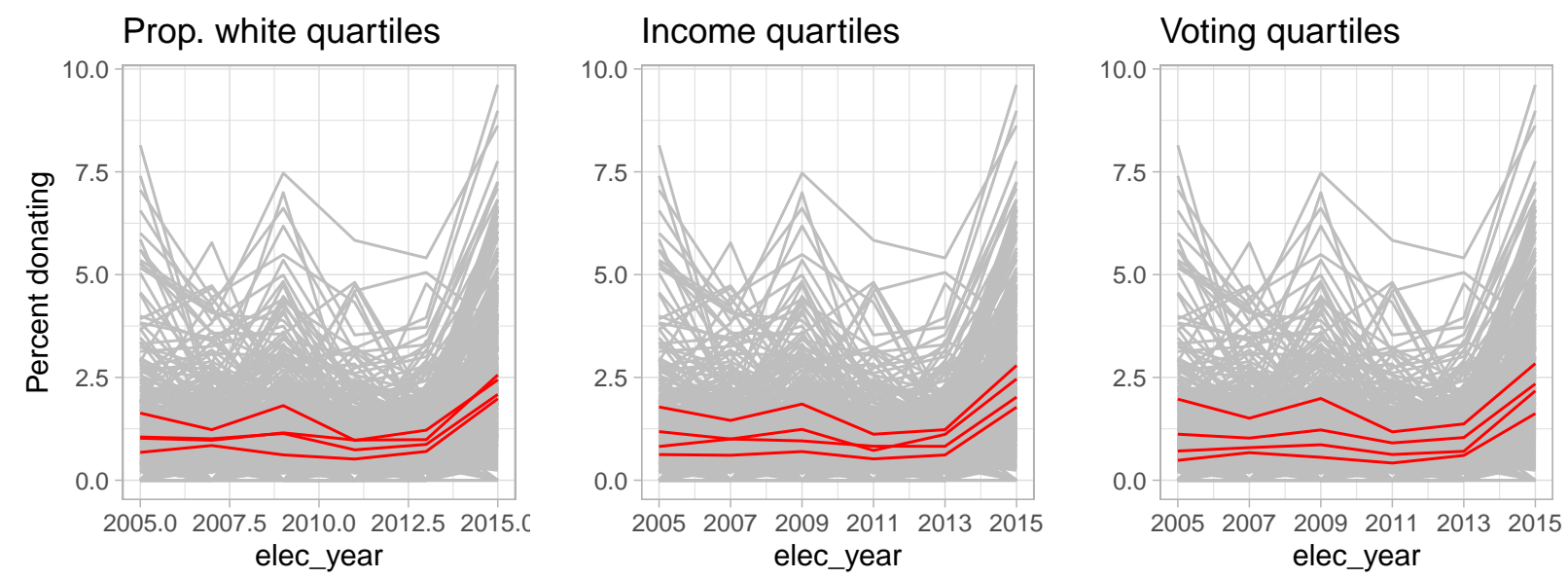

Figure 3 - Light gray lines are individual census blocks. Red lines represent quartiles averages. While not perfectly parallel, the quartiles certainly all move in tandem. 


\subsection{Model results using block group quartiles}

Table 7 - Relative to the underrepresented baselines, campaign finance participation increases the most in Democracy Voucher years for the most politically dominant groups.

\begin{tabular}{|c|c|c|c|c|}
\hline & \multicolumn{4}{|c|}{$\%$ Donating } \\
\hline & (1) & $(2)$ & $(3)$ & (4) \\
\hline VPP* votes (2nd quartile) & $\begin{array}{c}0.83 \\
(0.23)\end{array}$ & & & \\
\hline VPP*votes (3rd quartile) & $\begin{array}{c}1.29 \\
(0.22)\end{array}$ & & & \\
\hline VPP*votes (4th quartile) & $\begin{array}{c}2.02 \\
(0.25)\end{array}$ & & & \\
\hline VPP*\% white (2nd quartile) & & $\begin{array}{c}0.36 \\
(0.25)\end{array}$ & & \\
\hline VPP*\% white (3rd quartile) & & $\begin{array}{c}0.83 \\
(0.25)\end{array}$ & & \\
\hline VPP*\% white (4th quartile) & & $\begin{array}{c}1.43 \\
(0.26)\end{array}$ & & \\
\hline VPP*med income (2nd quartile) & & & $\begin{array}{c}0.67 \\
(0.25)\end{array}$ & \\
\hline VPP*med income (3rd quartile) & & & $\begin{array}{c}1.33 \\
(0.25)\end{array}$ & \\
\hline VPP*med income (4th quartile) & & & $\begin{array}{c}1.63 \\
(0.26)\end{array}$ & \\
\hline $\mathrm{VPP}^{*}$ conservative (2nd quartile) & & & & $\begin{array}{l}-0.04 \\
(0.24)\end{array}$ \\
\hline $\mathrm{VPP}^{*}$ conservative (3rd quartile) & & & & $\begin{array}{l}-1.00 \\
(0.23)\end{array}$ \\
\hline $\mathrm{VPP}^{*}$ conservative (4th quartile) & & & & $\begin{array}{l}-1.44 \\
(0.24) \\
\end{array}$ \\
\hline Observations & 3,808 & 3,808 & 3,808 & 3,304 \\
\hline
\end{tabular}

Each line is a census block group-cycle. Non-interacted terms are included within each model, but their output is suppressed. Votes is the mean count of times voted in 14 federal elections. Conservative represents mean Bonica contributor CF Scores within each block group. All models include block group and cycle fixed effects. Robust standard errors. 


\section{Dollar-weighted participation}

\subsection{DiD results using mean donation as the outcome}

\subsubsection{Census block groups}

Table 8 - When considering mean dollar donated instead of participation rates, overrepresented census tracts are more mobilized with Democracy Vouchers. Block and cycle fixed effects. Robust standard errors. Q stands for quartile.

\begin{tabular}{|c|c|c|c|c|c|c|c|c|}
\hline Mean Donation (\$) & (1) & $(2)$ & $(3)$ & (4) & $(5)$ & $(6)$ & $(7)$ & $(8)$ \\
\hline $\mathrm{VPP}^{*}$ vote index & $\begin{array}{c}1.01 \\
(0.17)\end{array}$ & & & & & & & \\
\hline $\mathrm{VPP}^{*}$ vote index_Q2 & & $\begin{array}{c}1.18 \\
(0.51)\end{array}$ & & & & & & \\
\hline $\mathrm{VPP}^{*}$ vote index_Q3 & & $\begin{array}{c}1.94 \\
(0.47)\end{array}$ & & & & & & \\
\hline $\mathrm{VPP}^{*}$ vote index_Q4 & & $\begin{array}{c}2.46 \\
(0.53)\end{array}$ & & & & & & \\
\hline $\mathrm{VPP}^{*}$ pct white & & & $\begin{array}{c}0.04 \\
(0.01)\end{array}$ & & & & & \\
\hline $\mathrm{VPP}^{*}$ pct white & & & & $\begin{array}{c}0.65 \\
(0.53)\end{array}$ & & & & \\
\hline $\mathrm{VPP}^{*}$ pct white_Q2 & & & & $\begin{array}{c}1.40 \\
(0.47)\end{array}$ & & & & \\
\hline VPP*pct white_Q3 & & & & $\begin{array}{c}2.15 \\
(0.49)\end{array}$ & & & & \\
\hline $\mathrm{VPP}^{*}$ pct white_Q4 & & & & & $\begin{array}{c}0.02 \\
(0.006)\end{array}$ & & & \\
\hline $\mathrm{VPP}^{*}$ med income_Q2 & & & & & & $\begin{array}{c}1.13 \\
(0.57)\end{array}$ & & \\
\hline $\mathrm{VPP}^{*}$ med income_Q3 & & & & & & $\begin{array}{c}1.83 \\
(0.54)\end{array}$ & & \\
\hline $\mathrm{VPP}^{*}$ med income_Q4 & & & & & & $\begin{array}{c}2.15 \\
(0.57)\end{array}$ & & \\
\hline $\mathrm{VPP}^{*}$ conservative & & & & & & & $\begin{array}{c}-2.36 \\
(.78)\end{array}$ & \\
\hline $\mathrm{VPP}^{*}$ conservative_Q2 & & & & & & & & $\begin{array}{c}0.17 \\
(0.48)\end{array}$ \\
\hline $\mathrm{VPP}^{*}$ conservative_Q3 & & & & & & & & $\begin{array}{l}-0.92 \\
(0.51)\end{array}$ \\
\hline $\mathrm{VPP}^{*}$ conservative_Q4 & & & & & & & & $\begin{array}{l}-1.49 \\
(0.52)\end{array}$ \\
\hline Observations & 3,808 & 3,808 & 3,808 & 3,808 & 3,808 & 3,808 & 3,304 & 3,304 \\
\hline
\end{tabular}




\subsubsection{Individual participation}

Table 9 - Controlling for different attributes, individuals in overrepresented groups are still benefitting the most from the Democracy Voucher program. Cycle and Individual fixed effects. Robust standard errors.

\begin{tabular}{|c|c|c|c|c|c|c|}
\hline & \multicolumn{6}{|c|}{ Mean Amount Donated $(\$)$} \\
\hline & $(1)$ & $(2)$ & $(3)$ & $(4)$ & $(5)$ & $(6)$ \\
\hline VPP*White & $\begin{array}{c}1.41 \\
(0.24)\end{array}$ & & & $\begin{array}{c}0.1 \\
(0.25)\end{array}$ & & \\
\hline VPP*Income Decile & & $\begin{array}{c}0.11 \\
(0.04)\end{array}$ & & $\begin{array}{c}0.11 \\
(0.04)\end{array}$ & & \\
\hline VPP*Voting Index & & & $\begin{array}{c}0.67 \\
(0.01)\end{array}$ & $\begin{array}{c}0.68 \\
(0.03)\end{array}$ & & \\
\hline VPP*Age (Under 70) & & & & & $\begin{array}{r}-0.008 \\
(0.01)\end{array}$ & \\
\hline VPP*Age (Over 70) & & & & & & $\begin{array}{l}-0.21 \\
(0.04) \\
\end{array}$ \\
\hline Observations & $1,327,016$ & $1,239,904$ & $1,327,016$ & $1,239,904$ & $1,176,236$ & 150,016 \\
\hline Cycle FE & Yes & Yes & Yes & Yes & Yes & Yes \\
\hline Indiv FE & Yes & Yes & Yes & Yes & Yes & Yes \\
\hline
\end{tabular}




\subsection{Over-time contribution trends, weighted by dollars}
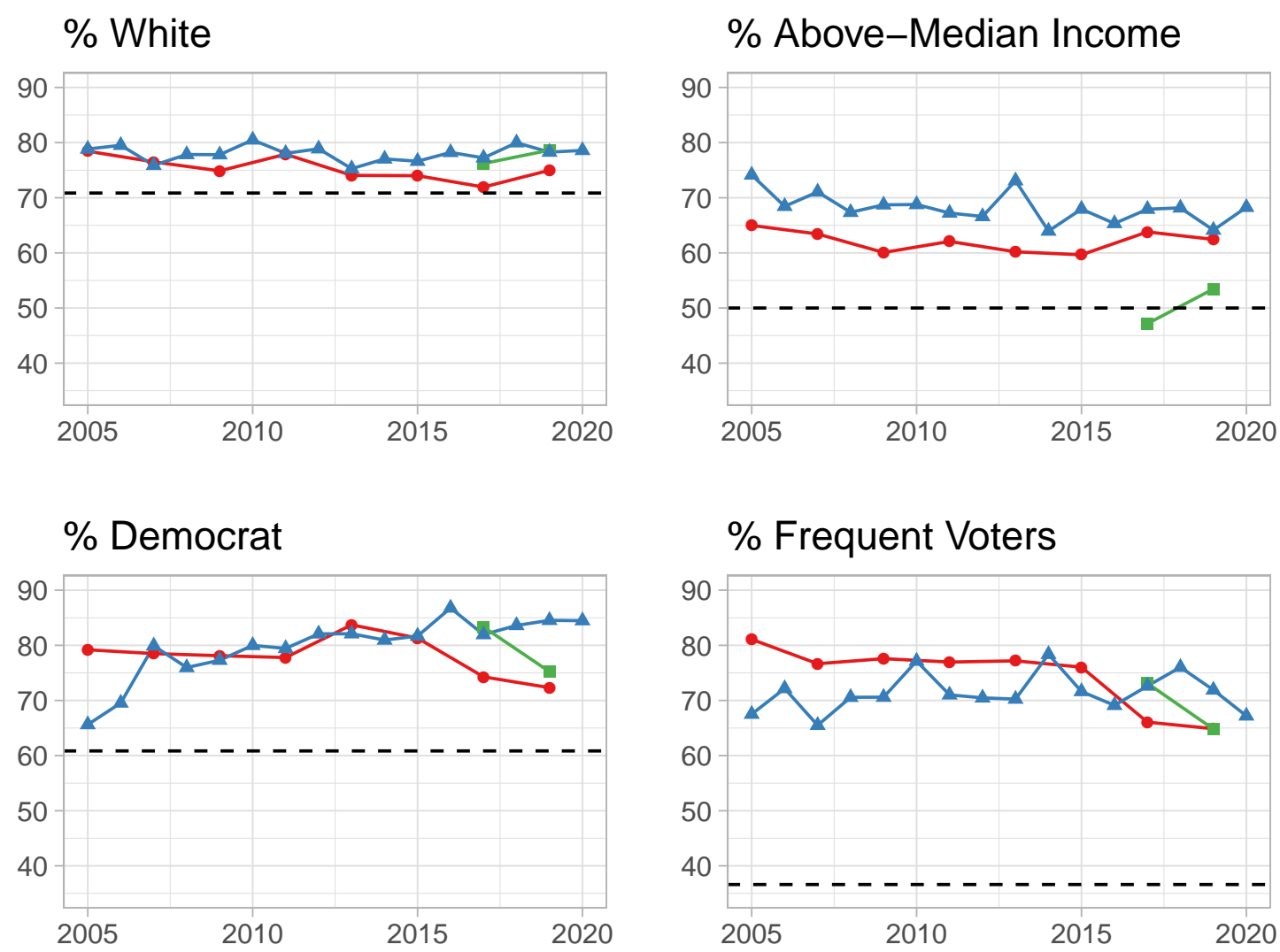

source $\rightarrow$ Muni cash $\_$Federal cash $\rightarrow$ Voucher

Figure 4 - Using dollar-weighted contributions instead of participation as a binary does not drastically change results. Except in the case of incomes, dollar-weighted contributions also reveal that already-overrepresented groups utilize Democracy Vouchers similarly or even more than they utilized cash. The dashed line represents the median among those within the constant Seattle panel. 


\section{Individual participation}

\subsection{Participation among the entire 2019 population}

Figure 5 - Democracy Voucher uptake is highest among demographics known to participate most in local politics.
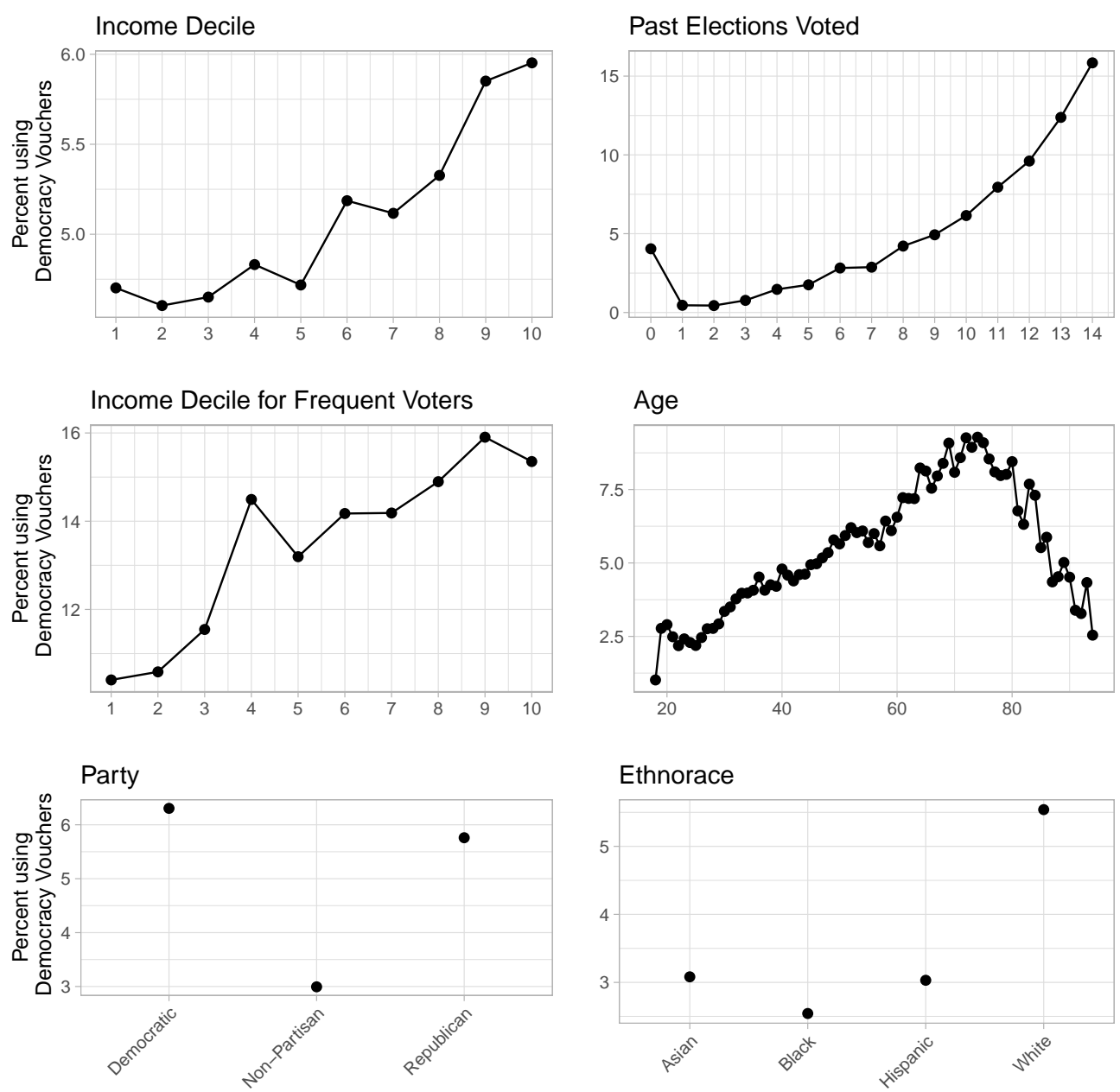

The full 2019 population mirrors the participatory patterns of the subset shown in Figure 1. 


\subsection{Relaxing the linearity assumption for individual income and participation models}

\subsubsection{Income Decile}

Table 10 - Treating income decile as a factor instead of a continuous variable confirms that the largest gains in the voucher-era come from individuals belonging to higher deciles. Cycle and individual fixed effects.

\begin{tabular}{lc}
\hline \hline & Dependent variable: \\
\cline { 2 - 2 } & Likelihood of donating $(\%)$ \\
\hline Decile $2 * \mathrm{VPP}$ & $-0.05(0.18)$ \\
Decile $3 * \mathrm{VPP}$ & $0.20(0.18)$ \\
Decile $4 * \mathrm{VPP}$ & $0.20(0.18)$ \\
Decile $5 * \mathrm{VPP}$ & $0.50(0.19)$ \\
Decile $6 * \mathrm{VPP}$ & $0.34(0.19)$ \\
Decile $7 * \mathrm{VPP}$ & $0.73(0.19)$ \\
Decile $8 * \mathrm{VPP}$ & $0.54(0.19)$ \\
Decile $9 * \mathrm{VPP}$ & $1.14(0.20)$ \\
Decile $10 * \mathrm{VPP}$ & $0.75(0.20)$ \\
\hline Observations & $1,239,904$ \\
\hline \hline
\end{tabular}




\subsubsection{Voting History}

Table 11 - Treating the index of past participation as a factor instead of a continuous variable confirms that the largest gains in the voucher-era come from individuals who have voted the most in the past. Cycle and Individual fixed effects and robust standard errors.

\begin{tabular}{lc}
\hline \hline & Dependent variable: \\
\cline { 2 - 2 } & Likelihood of donating $(\%)$ \\
\hline Voting Index 1*VPP & $0.37(0.13)$ \\
Voting Index 2*VPP & $0.35(0.12)$ \\
Voting Index $3^{*} \mathrm{VPP}$ & $0.63(0.12)$ \\
Voting Index 4*VPP & $1.21(0.13)$ \\
Voting Index 5*VPP & $1.36(0.12)$ \\
Voting Index 6*VPP & $1.83(0.12)$ \\
Voting Index $7^{*} \mathrm{VPP}$ & $2.41(0.13)$ \\
Voting Index $8^{*} \mathrm{VPP}$ & $3.06(0.13)$ \\
Voting Index $9^{*} \mathrm{VPP}$ & $3.83(0.14)$ \\
Voting Index 10*VPP & $4.67(0.15)$ \\
Voting Index 11*VPP & $5.76(0.16)$ \\
Voting Index 12*VPP & $6.80(0.16)$ \\
Voting Index 13*VPP & $8.58(0.17)$ \\
Voting Index 14*VPP & $11.06(0.16)$ \\
\hline Observations & $1,327,016$ \\
\hline \hline
\end{tabular}




\subsection{Participation among frequent voters}
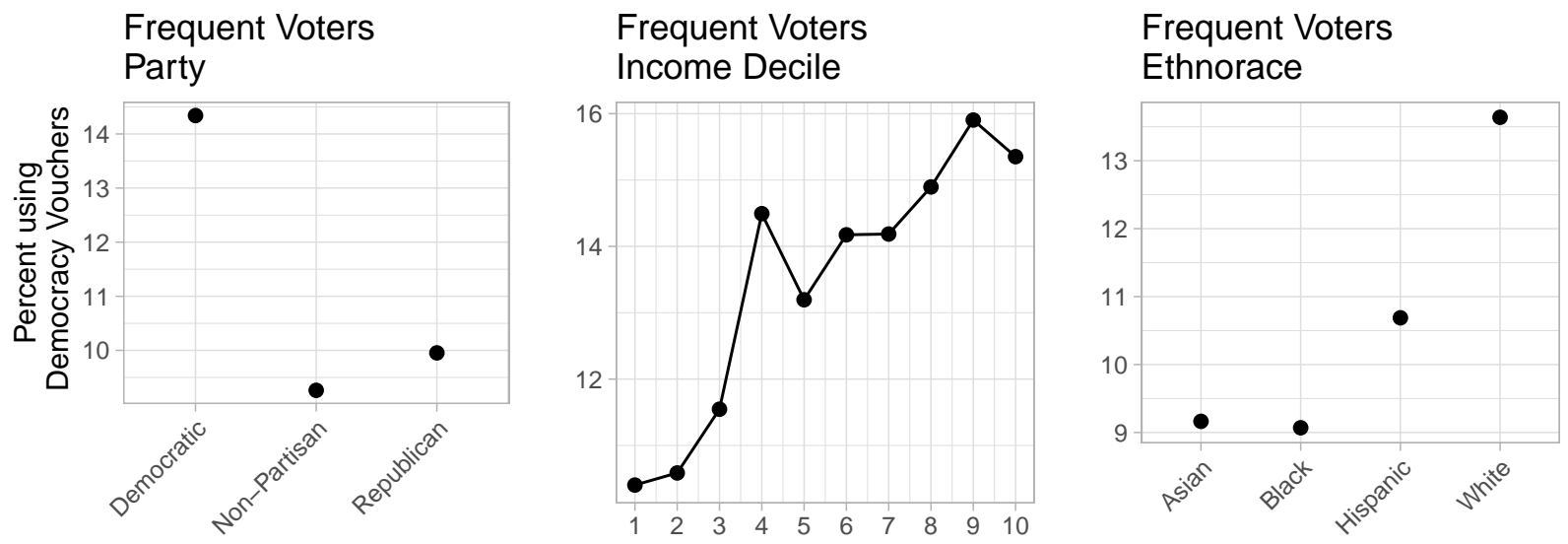

Figure 6 - Even among frequent voters (those who have participated in 12 or more of 14 previous federal elections), participation in the Democracy Voucher program is stratified by income, race, and party. 